\title{
Intercultural Music Teacher Education in Israel: Reimagining Religious Segregation Through Culturally Responsive Teaching
}

\author{
Amira Ehrlich and Belal Badarne
}

\begin{abstract}
This chapter is a result of a rare effort of interreligious dialogue between two colleagues in Israeli music teacher education - an Orthodox Jew and a devout Muslim. In this act of collegial sharing, intercultural conversation is used as an instrument for research. The documented effort to communicate respective culturally grounded perspectives to one another illuminates taken-for-granted norms and habits and expands respective understandings of cultural assumptions that currently underlie structures of religious segregation in Israeli music teacher education. Working to reimagine such structures, the authors question the possibility of interculturalism in the context of segregation. Tracing the constraints of cultural diversity further, considering policy and music teacher education, the authors re-imagine socio-religious segregation in Israeli music teacher education as an opportunity for culturally responsive teaching. The analysis and the envisioning are grounded in the experiences of the two authors as lecturers in two specialized segregated programs of music teacher education geared towards Arabic speaking populations and the Jewish Ultraorthodox community. Conclusions aspire towards cultural specificity within each community as a platform for future intercultural sharing that the authors believe can enrich Israeli society at large.
\end{abstract}

Keywords Music teacher education - Cultural diversity $\cdot$ Culturally responsive pedagogy

\footnotetext{
A. Ehrlich $(\bowtie)$

Faculty of Music Education, Levinsky College of Education, Tel Aviv, Israel

e-mail: amira.erlich@levinsky.ac.il

B. Badarne

Department of Education, Sakhnin College for Teacher Education, Sakhnin, Israel
}

H. Westerlund et al. (eds.), Visions for Intercultural Music Teacher Education, Landscapes: the Arts, Aesthetics, and Education 26, 


\section{Introduction: Exposing Cultural Assumptions Through Interreligious Dialogue}

This chapter is a result of a rare effort of interreligious dialogue between two Israeli music teacher educators: Amira - an Orthodox Jew, and Belal - a devout Muslim. As colleagues working together in Levinsky College's Faculty of Music Education in Tel Aviv, we have chosen to engage in dialogue to share with each other cultural perspectives of our profession. In this act of collegial sharing, we use intercultural conversation as an instrument for research (Blommaert 2010; Scollon Scollon and Jones 2012). During the course of two academic years, we documented monthly conversations that were structured using the concepts of sharing, co-interpreting, and reflecting on each other's work. The current chapter represents one of the important frames of conversation that emerged, which we present including some quotations from our conversational recordings.

We believe that our documented effort to communicate respective, culturally grounded perspectives to one another forced us to clarify, question, and reflect upon our own cultural and professional premises. The resulting insights illuminate takenfor-granted norms and habits of ourselves and of our surroundings, even as they expand our respective understandings of our own and each other's cultural impacts on our work (Badarne and Ehrlich in print; Barret 2011).

In the current chapter, we use such insights to expose cultural assumptions that currently underlie structures of religious segregation in Israeli music teacher education. Working to reimagine such structures, we question the possibility of interculturalism in the context of segregation, advocating cultural responsivity (Gay 2010; Lind and McKoy 2016), as one possible starting point.

Our conversation acknowledges the vast tradition of sociological discourse on segregation and multiculturalism (e.g. Baumann 1999; Munroe 2000; Woodson 2016), the scope of which is way beyond the limits of our current endeavor. We engage in this on-going scholarly discussion in contributing perspectives from our own lived experience. We challenge this discourse in suggesting a reframing of our specific cases of segregation in education as opportunities for promoting the values of diversity and inclusion rather than acts of suppression.

\subsection{Context}

The two authors of this chapter - Amira and Belal - live and work in opposite socioreligious poles of Israeli society. They first met as graduate students in music education in Levinsky College, and later became faculty members at this same institution. Levinsky's Faculty of Music Education includes three main tracks of undergraduate music education: (1) a general program aimed at all local populations, (2) a 
segregated track created for Jewish Ultraorthodox women, and (3) a separate track mostly populated by Arabic speaking populations. At the time this study was conducted, Amira was teaching in all three Faculty tracks, and Belal was teaching in the separate track for Arabic speaking populations. The purpose of our collaborative study was to explore each of our experiences in teaching within culturally segregated programs of music teacher education. As a starting point, we acknowledge that such programs do not exist in a vacuum, but rather echo norms of socio-religious segregation evident in Israeli social structures, and in Israeli public education.

\subsection{Israeli Norms of Socio-religious Segregation}

Interreligious dialogue in contemporary Israel is both a daily reality and a framework for social activism. In a previous collaboration (Badarne and Ehrlich in print) we have described our shared conception of a gap between social structures and everyday interactions between Jews and Arabs in contemporary Israel. Many basic infrastructures of Israeli society enact religious segregation: neighborhoods, towns and even entire cities are characterized by categories and sub-categories of religious affiliation (Carter 2007; Semyonov and Tyree 1981). Public education in Israel is mandated through a paradigm of linguistic segregation that translates into overall separation between Jews and non-Jewish populations (Elazar 1997; Tzameret 2003). At the same time, daily interactions at public places of commerce and culture often entail close contact between Jews and Arabs of diverse religious and ethnic affiliations. The gap between small, everyday encounters and structural segregation is further evident in the abundance of non-government organizations (NGOs) active in facilitating meaningful interreligious dialogue between Jews and Arabs in Israel (Kronish 2015). This gap is evident in music education as well as in music teacher education.

\subsection{Opening the Classroom Door}

Although it would be less common for an NGO to invest in the cultivation of institutional dialogue within a college of education, in many ways our commitment to collegial dialogue is no less important than the interreligious factor of our work. The universal stereotype of the closed classroom door, with each teacher autonomous and independent within his/her institution - in this case - is actually an accurate description of our professional context. Therefore, the mutual sharing between two lecturers of music teacher education working within the same institution is an additional layer of interaction that enabled us to write this chapter. 


\section{4 (How) Can Segregation Promote Inter-culturalism?}

In our current collaboration, this theme of opening the classroom door intersects with the interreligious effort, as we consider the challenges of Israeli music teacher education in relation to two segregated populations of contemporary Israeli society. Through the lens of intercultural frameworks, (Barrett 2011; Blommaert 2010; Gay 2010; Fitzpatrick 2012; Scollon et al. 2012; Talbot 2013), as researchers, we take interest in constraints and affordances that effect cultural contexts of music education. We believe that an explicit awareness of these cultural considerations is crucial for preparing pre-service teachers for the educational challenges that lie ahead. Such awareness is further required as a starting point to imagine a future of cultural enrichment working within each population that can subsequently act as a basis for intercultural sharing. Our current collaboration aims to outline cultural constraints and affordances of Israeli music teacher education as experienced in our respective practices.

We begin by outlining structures of socio-religious segregation in the Israeli education system. Interpreting Israeli music education policy as enforcing a standard of Western-Classical hegemony, we then trace the impact of this policy on institutional standards of music teacher education. The main focus of our conversation emerges as we explore the effects of these policy structures on our involvements in current institutional interventions of practice aimed at Arab and Jewish Ultraorthodox populations. Sharing our respective perspectives as active music teacher educators working within these specific cultures, we discuss future visions for a more culturally responsive music teacher education (Lind and McKoy 2016).

\section{Structures and Policy of Israeli (Music) Education}

Israeli public education is government mandated, and structured through a paradigm of socio-religious segregation. Four main streams of education exist as separate institutions, with separate inspectorates and curriculums for: (1) Jewish Secular, (2) Jewish Religious, (3) Jewish Ultraorthodox, and (4) Arabic speaking populations. While Jewish populations have been formally separated into sub-categories of religious affiliation, Arabic speaking populations including Muslim, Druze, Bedouin, and Christians all officially belong to one single, non-Jewish category. Several sub-categorizations and segregations of Arabic speaking groups exist defacto in some areas of Israel as a result of specific community considerations and/or geographical constraints (Jabareen and Agbaria 2014; Tzameret 2003). 


\subsection{Segregation That Facilitates Social Cohesion}

Elazar (1997) and Tzameret (2003) describe this sectarianism of Israeli State Education as a system based on civilizational and ideological principles, historically designed during the establishment of the State of Israel. Elazar (1997) interprets the irony entailed in such a system, by which the accommodation of sectarian differences in allowing different groups to pursue different visions resulted in creating a greater sense of social coherence, and even a sense of unity. Thus, in promoting segregated streams of education, historically, the Israel Ministry of Education has recognized the benefits of developing different curriculums for certain school subjects, as a catalyst for socio-religious and cultural diversity of Israeli society.

Historically speaking, the broadest example of this development is the 1953 legislation establishing the Jewish Religious stream of Israeli public education. Pre-State Jewish educational institutions existed in separate streams of education - separate schools for Zionist socialists, religious Zionists, and general Zionists (liberals); these later merged into the two basic streams of Israeli state education: a Jewish secular system and a Jewish religious State School system (Elazar 1997; Tzameret 2003). Tensions between the separate educational schools throughout the State's early history triggered political crises, the most dramatic case being the collapse of the Israeli government in 1951. At this time, a controversy over the division of new immigrants between secular and religious educational streams triggered a deep political divide that toppled the entire government (Tzameret 2003).

Ironically, the 1953 resolution legally recognized two segregated streams of public education - the secular and the religious. In this resolution, legislative segregation allowed the reestablishment and cohesion of a government that was impossible so long as the different visions of Israeli and Jewish education were conceptualized without it. The later educational reforms of Israel in the 1980s were similarly paradoxical, because they aimed at accommodating sectarian differences by allowing diverse groups to pursue different visions. In many subjects, such as history, literature, and civics, schools developed separate curriculums, teacher training, and textbooks to accommodate the difference between (1) secular Jewish schools, (2) religious Jewish schools, and (3) Arabic speaking populations. The more legitimacy government educational policy afforded to segregated difference, the greater the sense of social stability was (Elazar 1997).

Echoes of this seemingly paradoxical approach can be traced in current public discourse and debates on Israeli public education. Israeli President Rivlin's 2015 speech, which later came to be known as "The Speech of the Tribes,"1 described Israeli social order as constructed of four segregated tribes living in conflict. President Rivlin named the four main sectors of society as secular, religious, ultraorthodox, and Arab. Since 2015, this concept of conflicting "tribes" has become an explicit and dominant feature of Israeli public discourse. Indeed, Pew Research

\footnotetext{
${ }^{1}$ A Hebrew transcription of this speech can be read at: http://www.president.gov.il/ThePresident/ Speeches/Pages/news_070615_01.aspx
} 
Center's 2016 survey report on Israeli society proclaimed "deep divisions in Israeli society - not only between Israeli Jews and the country's Arab minority, but also among the religious subgroups that make up Israeli Jewry" (p. 5). The survey described Israeli Jewish identity as a "complex" entity (p. 6), constituted by a set of subcategories that function as "separate social worlds," and that are "reflected in starkly contrasting positions on many public policy questions" (p. 5).

Throughout 2017-2018 school year, Israeli media reported recurring allocations against religious foundations, allegedly infiltrating secular school systems as a form of religious coercion, as just another reminder of the ethos of separation that the Israeli government's status-quo agreements enforce and uphold (Ehrlich 2018). In 2017, the essence of President Rivlin's 2015 "tribes" speech, was translated into an activist initiative called "Israeli Hope." 2 The essence of its approach is evident in its double dedication to the fostering of internal cohesion within each sector, alongside a devotion to mutual respect of diversity, and acts of sharing. This Israeli approach to conflictual sectarianism thus deems the challenge of social cohesion no less important than the commitment to diversity, and conceptualizes segregation as an opportunity no less than as a challenge.

\subsection{Common Core in Music as Hegemony}

Notwithstanding the development of sectarian, differentiated curriculums in many school subjects, music and most arts subjects have been traditionally considered by the Israeli Ministry as "neutral enough" to be taught in a similar fashion, with similar standards within all sectors of Israeli society (Adler 2016). Within this context, music education is mandated through a single National Curriculum for all socioreligious sectors (Israel Ministry 2011). While allowing 30\% of content to include specialized electives that can be developed in respect to a local culture, the Curriculum is based on a common core principle in which Western-Classical contents and pedagogies function as the main mandatory constituents. Although we embrace the recognition of additional musical cultures as possible electives, we interpret the hierarchy of core knowledge in relation to electives as testimony to an overall Western-Classical hegemony.

Indeed, Ehrlich (2016) has expounded on the hegemonic structure of the single Israeli National Music Curriculum. She has further described a "kind of imagined (or real) exclusive dependence on Western repertoires and pedagogies as a function of personal, social, and institutional conceptualizations of professionalism in music and music education" in Israel. Analyzing the aspect of music in Early Childhood Israeli Curriculum, Gluschankof similarly summated this sense of absurdity, describing the State of Israel, as manifested through such educational structures, as "what has become a Western-oriented country situated in the Middle East" (2008, p. 37).

\footnotetext{
${ }^{2}$ https://www.israeli-hope.gov.il/
} 


\subsection{Israeli Music Education Caught in a Double Bind}

Interpreting the macro-structure of Israeli education alongside the micro-structure of Israeli music education, we perceive a double bind: the norm of socio-religious segregation in education at large, when combined with the Western-Classical hegemony of music education, seems to deny any prospect for cultural diversity. While the norms of segregation have been historically praised for allowing each sector to develop particular curriculums that cater to cultural specificity, the core of the National Curriculum of Music all but denies cultural specificity (Ehrlich 2016).

\section{Experiences in Current Institutional Interventions}

Working as Israeli music teacher educators, within this double bind, we have been taking part in current acts for social intervention towards diversity and inclusion. Levinsky College's Faculty of Music Education is active in the promotion of music teacher education in two socially segregated populations: Arabic speaking sectors and the Jewish Ultraorthodox sector. Over the past decade, the Faculty has developed specialized segregated tracks for music teacher education and accreditation.

As mentioned above, Levinsky's Faculty of Music Education currently includes three main tracks for undergraduate music education: (1) a general program aimed at all local populations, (2) a segregated track created for Jewish Ultraorthodox women, and (3) a separate track mostly populated by Arabic speaking populations. Currently, potential students of the Faculty can choose to study in the main socioreligiously-integrated programs, or choose the appropriate segregated parallel program.

As collaborating authors, we each have experience with the Arabic speaking classes: Amira as a cultural outsider, and Belal as an insider. Amira adds to this her experience in the Ultraorthodox program where she is somewhat of an insider. ${ }^{3}$ Sharing respective experiences of teaching within these segregated programs allowed us to reflect on what is, and on what can be, beyond policy and curriculum.

\subsection{Segregation That Enables Inclusion}

Amira described her experiences teaching in the women-only Jerusalem campus for music teacher education. This unique self-segregated campus was established to cater to the special cultural needs of the Jewish Ultraorthodox community. Strict

\footnotetext{
${ }^{3}$ Elaboration on sub-sectors of Israeli Judaism is beyond the scope of the current chapter. Some additional notes on this can be found in Badarne and Ehrlich (in print).
} 
social norms of complete sexual segregation, modest dress and behavior, and religious censorship of content, make it impossible for women of this sector to study in an integrated program. These norms affect program considerations of personnel, content, and pedagogies, and mandate that all must conform to cultural-religious dictates. Sharing her thoughts on this religiously and sexually segregated program, Amira recognized how segregation functions here as an enabling factor:

\begin{abstract}
Envisioning the future, I can see no real scope for change in terms of the Ultraorthodox segregated program. There is no way that religious leaders of this community will allow the women of their community to engage in studies that include musical performance in an integrated program. The segregated all-women's campus is an enabling factor, without which, I am afraid, women of this sector will not have access to this type of professional and academic study and accreditation.
\end{abstract}

Belal described the history of an additional effort to expand Levinsky's Music Education Faculty, through a partnership with the Safed Academic College, that lead to the establishment of a music teacher accreditation program, oriented towards Arab populations (including Muslims, Druze, and Christians) of the Northern Districts:

You know the title of this program is not 'Arab.' At first it seemed almost circumstantial that 99\% of the students enrolled in this program were Arab. Perhaps that is why no real thought was given to the details of the program - there was no thought or effort to culturally adapt, because, at first, the idea was that this was a geographically distinct program aimed at students from the North of the country. This has changed, and today - about ten years since its establishment - there is an effort to recognize and incorporate more Arab-based content and faculty members.

The initial motivation of this second segregated program was based on a geographical outreach, allowing students from the Northern districts of the country to complete their accreditation with minimal travel. Only as the program developed, did the cultural aspect of the student population became salient. The challenge of this program became manifested in the language gap between Arabic speaking students and a Hebrew speaking institution and staff. Belal and Amira agreed that this gap is not only linguistic, as it entails other cultural discrepancies, mainly between an aural-oriented tradition (Arab) and the centrality of music literacy and academia (Hebrew):

Amira: "I feel that the problems Jewish, Hebrew-speaking faculty have teaching in this program are not limited to language."

Belal: "Language is also culture, yes. But you have to understand where these students are coming from - it is not necessarily only the difference of Arab cultures, it is also a difference in the type of academic culture that they experienced at other institutions."

Amira: "Yes, I see. But even that has something to do also with the Arabic cultures and their epistemologies and educational practices."

Belal: "and - don't forget - the academic norms of more geographically peripheral institutions that are more lenient and less active in establishing academic standards of reading and writing."

Formal standards for acceptance and program curriculums are the same for all three of Levinsky's music education undergraduate programs. Nevertheless, as 
active faculty members of these programs both Belal and Amira attest to efforts towards inclusion of students whose cultural backgrounds differ from standard Western benchmarks. In collegial conversations with them, program directors and Faculty heads have expressed their perception of these segregated tracks as acts of social intervention, and described their work to expand potential student inclusion. During conversation, Amira recalled a Faculty meeting that she and Belal had attended, where one program director admitted to the group:

Efforts for inclusion sometimes entail creativity, for example, in investing in a wider perspective of in-depth interviewing, and in observing applicants within their own fields of practice, rather than depending solely on standardized institutional entrance exams.

Other specific examples of this came up in our dialogue:

Amira: "Actually, some of the women who are accepted to the Ultraorthodox music education program begin their music studies for the first time - they come in with no real musical background. Little to zero demand for previous knowledge is required - it is mostly a future-oriented approach, women who show some previous acquaintance with music, usually some high school music education, alongside a commitment to develop themselves professionally can be accepted. Some of these women choose vocal training as their lead instrument because they think it will be easier than starting an instrument so late in life."

Belal: "The same is true of some of the Arabic speaking populations. But also, there are several prominent and talented musicians from Arab communities who have no formal music education and have no chance of passing written exams, but when they perform, it is like 'wow'! Some of them are really great performing musicians, but they have no experience in reading Western notation, or understanding the basics of Western music theory, and so they cannot easily pass the exams. In my experience, I think all musicians should have Western music literacy as part of their training because I think this contributes to developing international professionalism. But if we accept only those students who already have this knowledge and skills we will be limiting the potential of the program."

\subsection{Constraining Musical Knowledge}

Even though acceptance standards are sometimes compromised for the benefit of broader inclusion, once students are accepted to either of the segregated programs, they must prove themselves in the same Western-oriented studies as those enrolled in the college's main integrated program. This often turns out to be no less challenging for the faculty teaching them, than for the students who have been accepted to learn. For the most part, the same faculty members teach in all three programs, with only minimum matching of a few, culturally affiliated faculty members within respective segregated programs. Belal explains:

Since the program is inclined towards Arabic speaking populations, you would think more could be done to accommodate these students. Most of them lack in-depth musical knowledge of Arabic musical traditions, and this is something they should be getting through the program and are not. Also, as far as language is concerned, there should be more space and preference for Arabic speaking teachers. 
Amira agrees:

In both segregated programs it often seems that all efforts are aimed at bringing the students to the content and level of the 'regular,' non-segregated program - as if that is the base, the standard. And I often wonder if more can be done to affirm and develop students' own culturally affiliated musical worlds. I have no doubt that the more they can interact with teachers from inside their own cultural worlds, this can happen more.

So, although the first important step has been taken towards broader inclusion and flexibility of the gateways into music teacher education, curriculums, course contents, and pedagogies have yet to undergo any major reconsideration. In many ways, Levinsky's Faculty of Music Education now echoes broader structures of Israeli music education where socio-religiously segregated groups of students share a single, hegemonic standard of teaching and learning. Even though public elementary and high school in Israel are socio-religiously segregated, all share the same Western, classically dominated, core music curriculum. At the same time, the college Faculty boasts two culturally segregated programs, but has done little work towards developing the cultural specificity of these programs' curriculums.

\section{Translation Instead of Transformation}

Levinsky's segregated music teacher education programs are based on a copy and paste of the curriculum that was previously established in the Faculty's integrated program. We interpret this approach as an act of translation rather than transformation. In a similar but broader gesture of intervention in Israeli music education, the Music Subject Committee of the Israel Ministry of Education commissioned a special task force in 2015 to create an Arabic version of the State Music Curriculum that was published in Hebrew in 2011. Again, this act was taken as an outward effort to recognize diversity and cater to culturally segregated populations. To date, however, we have witnessed most efforts being applied in the literal translation of existing policy documents from Hebrew into Arabic, rather than an overall reconsideration of the needs at hand.

\subsection{The Mystery of the Missing High-School Music Programs}

Our questioning of the effectiveness of such efforts is grounded in some lacunae that we have experienced in our respective fields of practice. In the Israeli public education system, there are currently over 130 registered high-school music-major programs dispersed throughout the country. All of these programs exist within the jurisdiction of Jewish school sectors. While several of these programs take place within schools that are open to non-Jewish populations, no high school music program exists in any school within the segregated Arab sector. The percentage of Jewish Ultraorthodox schools within this realm is also almost non-existent. Similar 
proportions exist in the realm of elementary school music, where over $80 \%$ of Jewish secular and Jewish religious schools teach music as a school subject, compared to almost non-existent percentages in Arab and Jewish Ultraorthodox schools (National Inspectorate of Music 2016).

This situation may not be surprising, considering that, in the most general terms that go far beyond music in education, both Arab and Jewish Ultraorthodox education systems have been repeatedly interpreted as lagging behind the Israeli publiceducation systems standards evident implemented in other sectors (e.g. Jabareen and Agbaria 2014; Perry-Hazan 2013). Socio-cultural constraints in Islamic decrees identify music as Harram (unholy), and both Islamic and Jewish conservative traditions associate music with licentious behavior (see e.g.: Badarne and Ehrlich in print; Dalal 2016; Shiloah 1992, 1997). These constraints may be effecting a low priority for music education within both religious contexts.

\subsection{Policy and Music Teacher Education: Who's the Chicken and Who's the Egg?}

Nevertheless, addressing this extensive lack of formal music education in Arab and Jewish Ultraorthodox schools, we believe that both policy and music teacher education have been instrumental in creating and perpetuating this situation. In terms of policy, for example, it is imperative to note that Israeli high-school musicmatriculation exams focus almost absolutely on Western-Classical traditions and literacy (Ehrlich 2016). These same traditions and literacy act as gatekeepers to most music programs in Israeli institutions of higher education, where potential music teachers receive state certification. Music teacher education for both the elementary and high-school levels is structured through this same hegemonic approach that shapes the high-school music-matriculation exam.

Indeed, describing the constraints of Arab music education in Israel, Dalal (2016) implicated Western musical literacy as distracting Arab youngsters from their native musical literacies - those that are predominately oral by nature, and include aural sensitivity to quarter tones that elude Western, well-tempered tuning. Dalal notes a positive shift that occurred in the mid 1990s with the opening of several nonWestern, undergraduate music programs that include dedicated training tracks for music teacher certification.

For the purpose of this current study, we have conducted an internet-based search of Isreali higher- education in music. Searching course descriptions and syllabi of such programs to-date within two Israeli accredited institutions of higher education that are leading this non-Western trend. Our findings reveal a persistent gap between non-Western content of music credits versus Western-dominated music education courses that comprise such programs. Perhaps, so long as Music Education policy stagnates within its Western-Classical paradigm, music teacher education must comply, while other undergraduate degrees are freer to pursue change. 


\section{3 “How Can I Teach What I Don't Know?"}

During our daily encounters with Israeli music teachers and music education students in college courses and Professional Development seminars, we have asked current and future music teachers from Arabic speaking and Jewish Ultraorthodox communities to respond to the idea of a more multicultural curriculum. Belal and Amira have each conducted several classroom discussion groups on this topic, as an integral part of the music pedagogy classes and professional development courses that they teach. These discussions with students were part of their routine classroom interaction, and Belal and Amira retrospectively summarized sentiments from such encounters and shared this data with each other. Both researchers found that during such discussion it was quite common for respondents to implicate music teacher education as responsible for their own lack of knowledge of "other" musics. Teachers often remarked: "how can I teach what I don't know". Such responses indicate patterns of exclusion, if interpreted as proof of the dominance WesternClassical knowledge.

Another interpretation of this response can point to gaps between teachers' perception of formal knowledge as the basis of classroom teaching, negating other informal or cultural knowledge that they may have. Indeed, both Arab and Jewish religious communities incorporate music in their community religious practices (Shiloah 1992, 1997). Be it the cantillation call to prayer of the Mosque, or the prayer-song within the synagogue, or the impressive musicianship of wedding ensembles, religiously-oriented communities of both faiths boast rich musical traditions. Many of these community-based practices rely on aural traditions and include unique musical expertise that cannot be represented using Western-Classical notation.

\section{Re-imaging Change}

We interpret Israeli music education as existing within a predicament of a double bind, with the socio-religious segregation of the Israeli school system on the one hand, and the hegemonic implications of a single National Curriculum of Music, on the other. Addressing the challenges of music teacher education within this system, we would like to envision possibilities of expanding repertoires and pedagogies in ways that may connect school music practices with the musical lives of our students. Like Gay (2010), we feel a need for more second-order change, one that can effect deep structures, and underlying assumptions, rather than allowing the incorporation of culturally specific musical practices as additional knowledge and secondary techniques. 


\subsection{Segregation as Opportunity}

Our experience has taught us that socio-religious segregation is sometimes crucial to allow for safe spaces and the existence of music teacher education where otherwise impossible (in terms of religious observances, language, and even geographical distances). Jewish Ultraorthdox women will never be allowed to engage in musical performance in the presence of any men or women beyond their own religious denomination. Arabic speaking populations were always a small minority in Levinsky's undergraduate music education programs before the separate program for Northern populations existed. Having a full class of Arabic-speaking future teachers encouraged discussion about the development of a culturally specific music curriculum - something that previously was overlooked or ignored.

Given the social segregation characteristic of the Israeli school system, we can imagine the possibilities of culturally responsive teaching (Gay 2010; GaztambideFernández 2011; Lind and McKoy 2016); and we imagine that segregation can become an opportunity to incorporate culturally specific musical expressions as legitimate and formal bodies of knowledge.

Lind and McKoy defined culturally responsive teaching as "a mindset that requires careful thought in regards to content, context, and instruction" (2016, p. 97). In a recent Faculty gathering, Belal presented an outline of musical knowledge relevant to Arabic speaking populations. This outline included central concepts of Arabic music theory (maqamat and rhythms) and of Arabic music history (genres, composers, and performers). Around the same time, in an exercise of curriculum planning, Amira challenged students of the Arabic-speaking program to suggest a potential high-school music curriculum that would be relevant to the youth of their own communities. Student efforts echoed Belal's outline, incorporating listening examples of artists such as Fairuz and Om Kalthoum, and composers such as Fared el Atrash and Mohamed Abdel Wahab. Students demonstrated how to use such examples to practice identification and replication of rhythmic patterns and maqamat improvisational techniques.

Throughout this exercise, Amira noticed that most of the Arabic students' lesson planning intuitively tended towards a more holistic approach, with theory, history, and repertoire intertwined in a way that Western pedagogies can only aspire to:

No matter what the starting point of any proposed lesson or unit was, the students always took care to move between listening, performing, and improvisational creativity, creating methodological and content-based links between these diverse learning activities.

Belal responded to Amira's experience:

Indeed, when you study an Eastern instrument in an Eastern tradition, your teacher will take responsibility for your theoretical knowledge in the most practical way. While you are studying performance, you are obviously gaining knowledge of the structures and functions of maqamat and rhythms, that allow improvisation and composition. I am not sure that this is how it works with a Western instrumental teacher. 
Thus, while both students and Faculty members are thus capable of envisioning a culturally relevant curriculum for Arabic-speaking populations, such a curriculum is not being systematically developed or implemented in teacher education or within schools. Amira expressed further criticism in the automatic adaptation of knowledge into Western formats, noting the tendency to perpetuate the Western split between music theory and music history rather than letting go of this dichotomy.

Amira expressed additional frustration toward the Ultraorthodox program, in what she experiences as a kind of ignorance of Christian, pagan, and secular underpinnings of Western repertoire and music history.

\footnotetext{
The Ultraorthodox suspicion of modernity has qualified anything 'classical' as kosher. Thus, as long as the music historically belongs to the Western classical tradition it is deemed as 'proper'. I often witness women singing or performing music taken from contexts quite opposite to Ultraorthodox standards of cultural purity, but the women are completely oblivious. Mozart's Aria 'Voi Che Sapete', for example, is a standard for beginning voice students. This aria is all about passion and desire that are forbidden for Ultraorthodox women to express so explicitly in public. I listen to them singing and wonder what their teacher has told them that the song is about.
}

Amira imagines that deep thought and awareness of such gaps between local cultural norms and cultural implications of the music involved could facilitate a music education that is much more aligned with the actual cultural values of this community. In her work, Amira has, for example, suggested incorporation of prayer song and even joyous dance tunes that are part of community life.

\section{Conclusions}

As music teacher educators acting for change, we negotiate possibilities within our classrooms and lecture halls, even as we lobby for policy reform. In doing so, we are opening up a space between policy and institutional dictates, and between dictates and practice. Such action begins even in a simple acknowledgement of GaztambideFernández' assertion that "the lives of all students are already filled with meaningful musical practices" (2011, p. 32). By encouraging students to bring such musics to class (via recording and/or live performance) we act to affirm the conceptualization of all musics as legitimate academic knowledge.

Engaging music education students from Arab and Jewish populations, we are guided by Gay's question: "How would teaching attitudes and behaviors differ if they emphasized talent, potential, and strengths of culturally diverse students, families, and communities instead of their problems and pathologies" (2010, p. 144). Rather than addressing Western notation as a mandatory, core departure point, we invite students to share and to explore their own musical lives, just as they live them. In doing so, we act to promote the musical agency of student-teachers, and invite them to be creative about repertoires and pedagogies that they are designing for future classrooms. 
For now, our work is limited to those individuals who have passed the gatekeepers of higher music education. Our hope is that such work may prove the value and necessity of expanding the cadre of music education students, even as it challenges policy frameworks.

We believe that social coherence may be promoted through local development of diverse musical practices that are more culturally aligned with their own specific Jewish and Arab communities than Western-Classical literacy. We imagine future efforts could then include frameworks for intercultural sharing based on cultural specificity rather than solely on the common core Western hegemonies. Finally, we suspect that Israeli society as a whole can benefit from the investment in such enriching diversity.

Culturally specific music education that balances internal community needs with intercommunity sharing can serve as an example of social activism that works to affirm cultural and religious diversity as a source of social vitality. In this way, Israeli music teacher educators can join in efforts to contribute to the complex matrix of socio-religious tensions, explicitly addressing the challenge affirm diversity, while exploring possibilities cohesion that do not undermine such affirmations. Such a professional standard can turn the field of music education into a social laboratory committed to experimenting with balances of diversity, inclusion, sharing, and cohesion: the core challenges of Israeli society and of all other multicultural societies.

\section{References}

Adler, S. (2016). National Religious State Education. Presentation at Mandel Institute of Educational Leadership, Jerusalem.

Badarne, B., \& Ehrlich, A. (in print). Dancing on the limits: An interreligious dialogue exploring the lived experience of two religiously observant music educators in Israel. In A. Kallio, P. Alperson \& H. Westerlund (Eds.), Perspectives on music, education and religion: A critical inquiry. Bloomington: Indiana University Press.

Barrett, M. S. (2011). A cultural psychology of music education. Oxford: Oxford University Press.

Baumann, G. (1999). The multicultural riddle: Rethinking national, ethnic, and religious identities (Zones of religion). New York: Routledge.

Blommaert, J. (2010). The sociolinguistics of globalization. Cambridge: Cambridge University Press.

Carter, G. R. (2007). Learning together, living together. Educational Leadership, 65(2), 82-84.

Dalal, I. (2016). HaChinuch hamusicali ba'migzar ha'Aravi [Music education in the Arab sector]. Presentation at Israeli Musicological Society Winter Conference, Tel Aviv.

Ehrlich, A. (2016). Dictating "diversity": A case of how language constructs policy in Israeli music education. Finnish Journal of Music Education, 19(2), 30-47.

Ehrlich, A. (2018). Pray, play, teach: Conversations with three Jewish Israeli music educators. Unpublished doctoral dissertation, Boston University.

Elazar, D. (1997). Education in a society at a crossroads: An historical perspective on Israeli schooling. Israel Studies, 2(2), 40-65.

Fitzpatrick, K. R. (2012). Cultural diversity and the formation of identity: Our role as music teachers. Music Educators Journal, 98(4), 53-59. 
Gay, G. (2010). Acting on beliefs in teacher education for cultural diversity. Journal of Teacher Education, 61(1-2), 143-152.

Gaztambide-Fernández, R. A. (2011). Musicking in the city: Reconceptualizing urban music education as cultural practice. Action, Criticism, and Theory for Music Education, 10(1), 15-46.

Gluschankof, C. (2008). Music everywhere: Overt and covert, official and unofficial early childhood music education policies and practices in Israel. Arts Education Policy Review, 109(3), $37-46$.

Israel Ministry of Education. (2011). Musica: Tochnit limudim [Music: A curriculum]. Tel-Aviv: Ma'alot.

Jabareen, Y., \& Agbaria, A. K. (2014). Otonomiya LaHinuch HaAravi BiIsrael [Autonomy for Arab education in Israel]. Giluyi Daat, 5, 13-40.

Kronish, R. (2015). Coexistence \& reconciliation in Israel: Voices for interreligious dialogue. Mahwah: Paulist Press.

Lind, V. R., \& McKoy, C. L. (2016). Culturally responsive teaching in music education. New York City: Routledge.

Munroe, M. E. R. (2000). Unamerican tail: Of segregation and multicultural education. Albany Law Review, 64(1), 241-308.

National Inspectorate of Music. (2016). Presentation at the Dostrovsky forum for music and dance education. Jerusalem: Van Leer Institute.

Perry-Hazan, L. (2013). Hahinuch haharedi bilsrael [The ultraorthodox education in Israel]. Jerusalem: Hebrew University.

Semyonov, M. \& Andrea, T. (1981). Community segregation and the costs of ethnic subordination. Social Forces, 59(3), 649-666.

Scollon, R., Scollon, S. W., \& Jones, R. H. (2012). Intercultural communication a discourse approach (3rd ed.). Chichester: Wiley-Blackwell.

Shiloah, A. (1992). Jewish musical traditions. Detroit: Wayne State University Press.

Shiloah, A. (1997). Music and religion in Islam. Acta Musicologica, 69(2), 143-155.

Talbot, B. C. (2013). Discourse analysis as potential for re-visioning music education. Action, Criticism, and Theory for Music Education, 12(1), 47-63.

Tzameret, T. (2003). Hahinuch baasor harishon [Education in the first decade]. Tel Aviv: Open University.

Woodson, K. (2016). Diversity without integration. Penn State Law Review, 120(3), 807-866.

Open Access This chapter is licensed under the terms of the Creative Commons Attribution 4.0 International License (http://creativecommons.org/licenses/by/4.0/), which permits use, sharing, adaptation, distribution and reproduction in any medium or format, as long as you give appropriate credit to the original author(s) and the source, provide a link to the Creative Commons licence and indicate if changes were made.

The images or other third party material in this chapter are included in the chapter's Creative Commons licence, unless indicated otherwise in a credit line to the material. If material is not included in the chapter's Creative Commons licence and your intended use is not permitted by statutory regulation or exceeds the permitted use, you will need to obtain permission directly from the copyright holder.

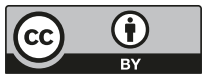

